\title{
Vaccination communication strategies: What have we learned, and lost, in 200 years?
}

\section{Merryn McKinnon and Lindy A. Orthia}

\begin{abstract}
This study compares Australian government vaccination campaigns from two very different time periods, the early nineteenth century (1803-24) and the early twenty-first (2016). It explores the modes of rhetoric and frames that government officials used in each period to encourage parents to vaccinate their children. The analysis shows that modern campaigns rely primarily on scientific fact, whereas 200 years ago personal stories and emotional appeals were more common. We argue that a return to the old ways may be needed to address vaccine hesitancy around the world.
\end{abstract}

Keywords

Health communication; History of public communication of science; Science and policy-making

Vaccination campaigns have had mixed success across the world over the past two centuries. While western science has almost invariably insisted that vaccines are safe and effective, publics have still expressed doubts and fears, and have often resisted the scientific perspective.

Boddice [2016, p. 71] recently argued that, historically, public fears about vaccination have almost always been manifestations of the same three things: ignorance; political ideology regarding individual liberty or mistrust of establishment interests; and/or "moral panic or ethical misgivings related to religion, sex and class." He said these objections have existed since Jenner developed the original vaccine against smallpox, at which time genuine uncertainties about safety raised understandable objections to compulsory vaccination [Durbach, 2000; Mark and Rigau-Pérez, 2009; Murdoch, 2015]. However, similar objections reappeared in subsequent anti-vaccination campaigns across the world, despite further research rendering many uncertainties moot. In particular, the global politics of western science, capitalism and European imperialism continue to generate mistrust and fear about medical interventions. Boddice reiterated a point familiar to science communicators, that "Antivaccinist ignorance cannot merely be met with education about vaccine safety and efficacy, since the agencies that produce such fact-based pedagogy are perceived to be part of the problem" [p. 74]. As a result, he argued historians can play a key role in combatting unfounded anti-vaccination sentiment, by identifying "from where the structures of doubt and fear come" [Boddice, 2016, p. 74]. 
The present paper is a response to Boddice's suggestion, but from the other side of the equation. Rather than examining public fears, we here compare strategies governments used in different historical periods to promote vaccination and alleviate those fears. We use Australia as a case study, and compare strategies 200 years apart: government-endorsed smallpox vaccination campaigns from the early nineteenth century, and government-produced immunisation materials from the twenty-first century. Accepting Boddice's assertion that public fears have not changed in that time, we ask: have Australian government strategies changed in 200 years?

Public perceptions of vaccines internationally
Despite high levels of vaccine compliance, Australia is experiencing increasing vaccine hesitancy, which is also seen globally [Danchin and Nolan, 2014; Leask, Willaby and Kaufman, 2014]. Vaccine hesitancy includes barriers from a range of personal attitudes, beliefs and, subsequently, behaviours such as vaccine refusal or intentional delay [Smith, 2015]. It is not a new phenomenon, as implied by Boddice [2016]. However it is possible that vaccine hesitancy is increasing now because of the 'crowded' vaccination schedule along with "greater access to, and more rapid dissemination of, vaccine-critical messages via digital networks" [Leask, Willaby and Kaufman, 2014, p. 2600]. Lack of awareness of the need to vaccinate is one key factor in people not getting vaccinations [Collins et al., 2014]. Doubts about vaccine safety also contribute to hesitancy, even if people receive information specifically addressing such concerns, as seen for the human papilloma virus vaccine [Tung, Machalek and Garland, 2016]. Both factors reiterate two of Boddice's identified objections: ignorance and ideology respectively.

The news media, both 'new' and 'traditional', are key players in the communication of vaccination messages, as are social media sites such as Facebook. A study of comments on an online news article from a Canadian newspaper found that there were distinct themes in the posts of vaccine supporters, notably societal responsibility to ensure herd immunity, the prevention of the spread of disease and the desire to refute misinformation [Pereira et al., 2013]. Commenters who were against vaccination typically described vaccination as a personal rather than societal choice, and expressed distrust of vaccine manufacturers [Pereira et al., 2013], responses which resonate with the types of objection identified by Boddice [2016]. Pereira and colleagues also found that anti-vaccine comments were disproportionally higher in number than those supporting vaccination. McKeever et al. [2016] similarly found mothers who do not support childhood vaccination are far more likely to engage in online communication which could affect public opinion and perception. This suggests that government agencies seeking to promote vaccination need to use these outlets to help disseminate their message; indeed, collaboration between researchers, health care providers, policy makers and journalists is imperative to ensure complete and accurate information is disseminated [Perez et al., 2016].

In addition to reconsidering communication media, the literature suggests government agencies need to shift away from merely reiterating safety and efficacy messages. Fear based campaigns by health authorities have been used effectively in the past to raise awareness of issues such as lung cancer and HIV [Leshner, Bolls and Thomas, 2009]. These campaigns have been effective in getting attention, however more recent studies have suggested that using positive emotional 
language may lead to greater sharing of health messages, as seen in the 'Ice Bucket Challenge' [Bail, 2016]. Bail [2016] concluded that public health organizations cannot control how people will respond to a message, but simply describing recent advances or scientific information will not engage their target audience. They need to attempt to connect the emotions their audience may feel, such as fear or uncertainty about vaccine safety, to the information they provide, and genuinely attempt to address those fears without goading further negative emotional response. This perspective reinforces what the science communication literature has already demonstrated with respect to diverse issues: facts alone are not enough [Bray, France and Gilbert, 2012], there are issues of trust between scientific authorities and publics [Bauer, Allum and Miller, 2007], and factors such as beliefs and values must be considered to understand the influences on personal stances and interpretations of issues [McCall and Groark, 2007; Mikulak, 2011].

One government-funded (but not government run) Australian vaccination campaign illustrated the importance of questions of targeted values and identity. The I Immunise campaign from Western Australia targeted a known 'alternative' lifestyle community with lower than national average vaccination rates [Attwell and Freeman, 2015]. The campaign featured local parents who vaccinated their children and also identified as living an 'alternative' lifestyle. It used billboards, posters, newspaper advertisements and social media, with 300-word testimonials from parents outlining how vaccination fit into their lifestyle. Evaluation of the campaign showed mixed success, reaching one third of non-vaccinators, with most respondents $(77 \%, n=304)$ reacting positively but others more negatively about vaccination [Attwell and Freeman, 2015]. The authors argue that this campaign indicates a values-based approach could be useful for reaching this audience.

For these reasons we here evaluate Australian government vaccination strategies using three tools: Aristotle's modes of rhetoric, Nisbet and Scheufele's [2007] eight frames for reporting on science-related issues, and Boddice's three causes of public fear. Aristotle's distinction between logos (fact-based logical arguments), pathos (emotive arguments) and ethos (argument by asserting expertise) has remained a useful approach to rhetorical analysis for centuries, and can determine the prevalence of facts-based versus values-based approaches [Tirdatov, 2014]. Nisbet and Scheufele's frames illuminate the perceived persuasive currency of different ways of representing science. They facilitate the simplification of complex issues [Nisbet and Scheufele, 2007], and they reoccur in science debates, irrespective of the topic being 'debated' [Nisbet and Lewenstein, 2002]. We use these tools along with Boddice's insights to describe the rhetorical and framing means by which governments have attempted to persuade the public to vaccinate, and whether they have addressed public fears.

The Australian situation historically and today
Australia has relatively high and stable immunisation rates, currently ranging from 90-93\% [Australian Government, 2016b]. These rates are based on the number of children registered as 'fully immunised', meaning they have received all recommended vaccines by the recommended age. However, the national aspirational immunisation coverage target is $95 \%$ - a level exceeding that needed to ensure herd immunity against measles, the most infectious vaccine preventable disease [Australian Government, 2016a; Australian Government, 2016b]. Since campaigns alone have not been fully effective at increasing vaccination rates to the 
aspirational level, the Australian Government introduced legislation in 2016 tying immunisation to welfare benefits and childcare access [National Centre for Immunisation Research \& Surveillance, 2016]. This produced immediate increases in child vaccination, but it has been controversial for penalizing recent migrants and people on lower incomes [Hendel, 2016; Marriner, 2016; Peatling, 2015]. It would therefore be ideal to improve campaign success without resorting to state coercion. We hoped that understanding how vaccination campaigns have evolved in Australia would shed light on which strategies are effective and which have not been fully explored. We chose Australia's first vaccination campaign period and the present day as two snapshots for characterising this evolution.

Our first snapshot concerns the early colonial period. In 1788 Britain colonised the already occupied Australian continent, establishing the penal colony of New South Wales, which later became one of the states of Australia. The years 1803-24 saw the first attempts to introduce cowpox into the colony to vaccinate against smallpox. This was contemporaneous with what Mark and Rigau-Pérez [2009] describe as the world's first vaccination campaign, the Spanish government's campaign across its global territories. During this period, New South Wales was ruled by a local governor and his officers on behalf of the British monarch, and it is primarily their voices that comprise the government campaign for our study.

When cowpox vaccine was successfully introduced in 1804, officials strongly encouraged child vaccination. A controlled vaccination program was urgent both to protect people from smallpox, and because the vaccine material had to be transmitted from vaccinated to unvaccinated people at a specific stage in the cowpox scab's development to stay viable. If this window for transmission was missed, the colony would lose the vaccine, as keeping it alive during ocean transit was extremely difficult [Bennett, 2009; Bhattacharya and Brimnes, 2009]. Colony officials cultivated cowpox by serially vaccinating orphans under state care, but afterward appealed to volunteers to keep it viable. Ultimately the vaccine was re-introduced three more times during our period, in 1809, 1818 and 1822 [Bennett, 2009].

There were no smallpox outbreaks during this time, which may suggest the vaccination campaigns were quite successful. However, Australia was somewhat protected from smallpox by being surrounded by ocean, so that remains uncertain. The campaign material we discuss here suggests many people were vaccinated in the colony but there were still parents who did not vaccinate their children. Data about colonial public attitudes towards vaccination are scant, so it is not entirely clear why some parents did not vaccinate, but the colony's substantial British population suggests there are likely similarities with the British public attitudes discussed by Boddice. Certainly the level of knowledge about vaccination would have been comparable. Most of the population in the colonial settlements were convicts, ex-convicts or convicts' children, and they had obvious reason to mistrust authority and desire individual liberty. Convict theatre troupes performed at least three plays critical of medical practitioners, perhaps indicating suspicion of that profession [Orthia, 2016]. The preponderance of poverty crimes as reasons for transportation, and the visible use of poor children to incubate the vaccine, would surely have cultivated class-related objections. The ways government communications addressed these circumstances in their campaign material is a question for this study. Beyond the colonial settlements, Aboriginal and Torres 
Strait Islander peoples comprised the vast majority of people living on the Australian continent, and some Aboriginal people also lived in and around the British settlements. The historical record is unclear on whether vaccination was offered to Aboriginal people in the time period of interest, though it was offered later on an ad hoc basis, particularly during smallpox outbreaks [McWhirter, 2008, pp.312-316].

The primary channel through which colony officials campaigned for vaccination was Australia's first newspaper, the Sydney Gazette. The Gazette was censored by the governor and its primary function was to distribute government orders, though it included other material. We use the Gazette's smallpox articles as our source material for this first period, because they represented the endorsed government position and are therefore comparable to contemporary Australian government communications. We end the first period in 1824, when the colony acquired some self-government and a free press, changing the cultural landscape.

The material for our second snapshot was taken from the present day (2016). Since the days of Jenner, the range and number of vaccine preventable diseases has increased markedly. The Immunise Australia Program's childhood vaccination schedule includes vaccinations against 16 diseases, administered up to 15 years of age, with the majority given between birth and four years [Australian Government, 2015; Australian Government, 2016a] Australian state and territory government health departments and Australia's national immunisation plan all play a role in promoting this schedule. We therefore selected documents from each of these authorities to compare with the Gazette articles, since together they represent the breadth of the official government position.

We downloaded all Sydney Gazette issues for the period electronically, and searched for relevant articles using the terms pox, smallpox, cow pock, virus, vacc, inocu, variol, Jenner, and spelling variations. Articles peripheral to the vaccination campaign were included as we considered them part of the same discursive environment (e.g. an article comparing the cause of plague to that of smallpox). Articles mentioning smallpox or vaccination only trivially were excluded.

For 2016 government publications, all state and territory health department websites were searched for immunisation pages (retrieved between 1-14 October 2016). Websites were used as the internet and social media have a significant role in influencing vaccine attitudes and behaviours [Stahl et al., 2016]. Therefore these texts represent the official government position in a communication channel dominated by anti-vaccine sites [Bean, 2011]. Each state and territory had at least one page outlining why people should immunise and/or the benefits of immunisation as well as practicalities of what vaccines are available and where. These generic pages were included in the sample. Some states linked to additional relevant documents which were also included. For example Queensland's information page linked to a brochure for parents to help choose whether to immunise their children, and South Australia had brochures and posters targeting parents and caregivers of Aboriginal children. Victoria had a separate campaign, Immunity for Community, delivered via short testimonial videos on their 
designated online health channel. We included these video transcripts, and one from New South Wales, within the sample.

We also included material from the national Immunise Australia Program's comprehensive website for the public and health professionals. To ensure comparability, we only sampled information from the website's 'why immunise' section, as it was deemed the source of information most likely to target parents. In the following, we refer to each discrete component of 2016 material as a 'text'.

\section{Sample characteristics}

The Sydney Gazette printed 46 articles about vaccination and/or smallpox between 1803 and 1824. Two repeat printings of an 1818 Government Order were excluded from analysis, bringing the final dataset to 44 articles. Lengths varied from a 13 word news item to 1334 word Royal Jennerian Society campaign material (median $=397$ words). Twenty one articles concerned the colony's vaccination progress. Six were concerned primarily with the science of vaccination, including the Jennerian Society material printed in 1804 and the 1818 Government Order which reworked it. Twelve articles reported overseas news about vaccination/smallpox. Five made other remarks, for example a historical note about treating smallpox by bleeding.

For the 2016 dataset, 19 texts were collected from national, state and territory government websites. The amount of information provided by each government on the general information pages varied from around 200 words for the Northern Territory, to more than 800 words for Queensland. The additional materials also varied in length.

\section{Analysis}

We used three analytical approaches to characterize each period's campaign strategy.

1. We identified the presence or absence of logos, pathos and ethos in each article or text.

2. We identified the presence or absence in each article or text of Nisbet and Scheufele's eight frames.

3. We searched for the presence or absence of the three types of objection Boddice listed, to understand how the government in each period implicitly characterized the vaccine hesitancy problem.

Each author initially coded the materials for one period. We then cross-coded for each other, discussed discrepancies and diverse interpretations of the analytical categories, and came to a consensus view [Markic and Eilks, 2013]. Coding discrepancies were minor and easily resolved. Most differences were the presence or absence of a particular frame or Aristotlean rhetoric. Differences of opinion - limited to about five percent of the whole sample- were discussed, and a consensus opinion formed. 
In the following we describe the major trends that emerged for each of the two eras, and then compare them to evaluate what has changed in 200 years and the significance of those changes. Our approach to reporting the results is primarily qualitative, but we also report some percentages to indicate the magnitude of the trends identified. Our quantitative reporting has limitations though because defining what constituted a single unit of analysis was problematic. Some Gazette articles referred to another article in the same issue, so both could have been classified as a single unit, though we treated each as separate. For the 2016 material it was difficult to differentiate between 'texts' because of the interconnected nature of websites. We treated each website proper as one text, plus each linked document as an additional text, however we acknowledge alternative, but not necessarily better, choices could have been made. There is an inherent bias towards a trait being coded 'present' in a 2016 text because each text is more all-encompassing than some of the brief Gazette articles. Therefore, the reported percentages should be treated with caution.

Perhaps unsurprisingly, logos was the rhetorical mode most commonly employed in both eras. It varied from simple factual statements such as "Immunisation is a simple and effective way of protecting children and adults against certain diseases" (Queensland - Benefits of Immunisation) to more specific information such as "One in 6 who have the disease [smallpox] dies; at least half of Mankind have it, consequently one in 12 of the human race perish by one disease!!" (Sydney Gazette, 13 May 1804). Logos appeared in 75\% of Gazette articles, primarily to describe smallpox's effects; the vaccine's traits, safety and effects; and actions taken to vaccinate the colonial population or the consequences if no one should volunteer to be vaccinated (quantitative results summarized in Figure 1). It was the dominant rhetorical mode in all article types aside from local news. In the 2016 dataset, logos was used in $84 \%$ of texts, and was dominant in messages conveying why people should immunise. In every state and territory text, logos was used to outline how vaccinations worked, who benefits from them, and which were available.

Ethos was used to persuade readers in $64 \%$ of Gazette articles, usually by attributing a statement to someone in authority or noting their endorsement of vaccination. The most commonly mentioned authorities were medical doctors, including Jenner and other European experts (or simply "a gentleman of the Faculty"), and the colonial medical authorities including the Principal Surgeon. The British Government, New South Wales Governor or Royal Family were also mentioned regularly. In the 2016 material, ethos was used less often, in only $53 \%$ of texts. It was also used more narrowly, typically regarding vaccine safety. It usually referred to publicly funded scientific organizations and established scientific processes for testing safety. For example, the National Immunisation Program 'Putting Safety First' material stated: "All vaccines... are rigorously tested on thousands of people in progressively larger clinical trials."

There was a striking difference in the use of pathos between the two eras. Pathos appeared in $61 \%$ of Gazette articles, most often local news, becoming dominant in some. It manifested primarily in two ways. The first was an emotive turn of phrase 
(a)

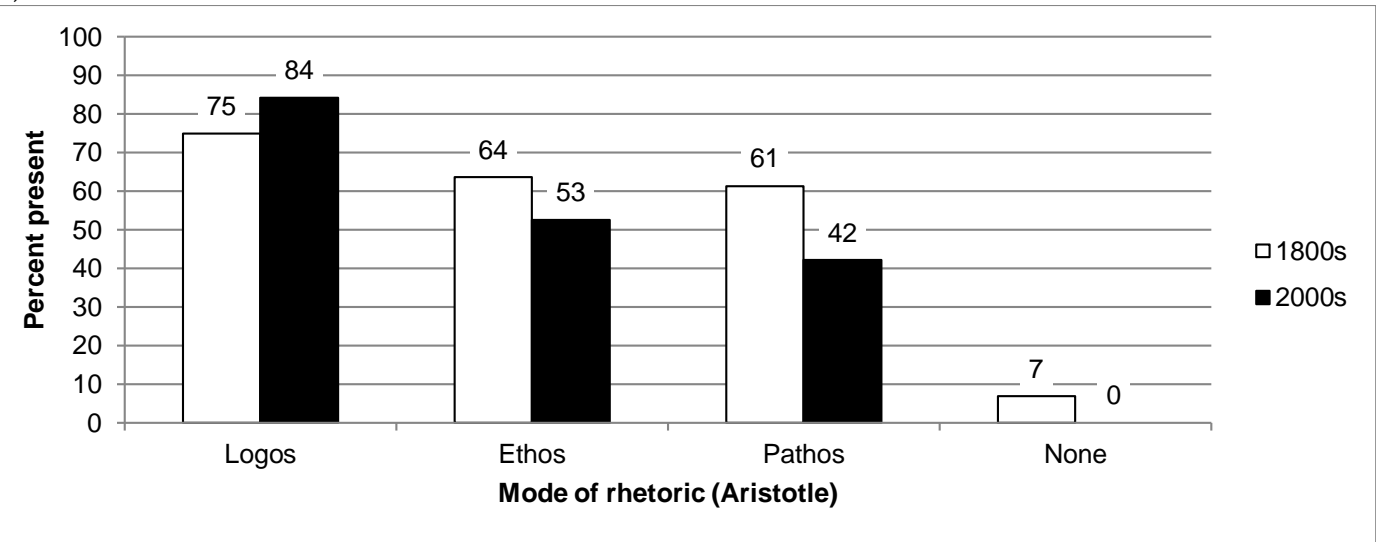

(b)

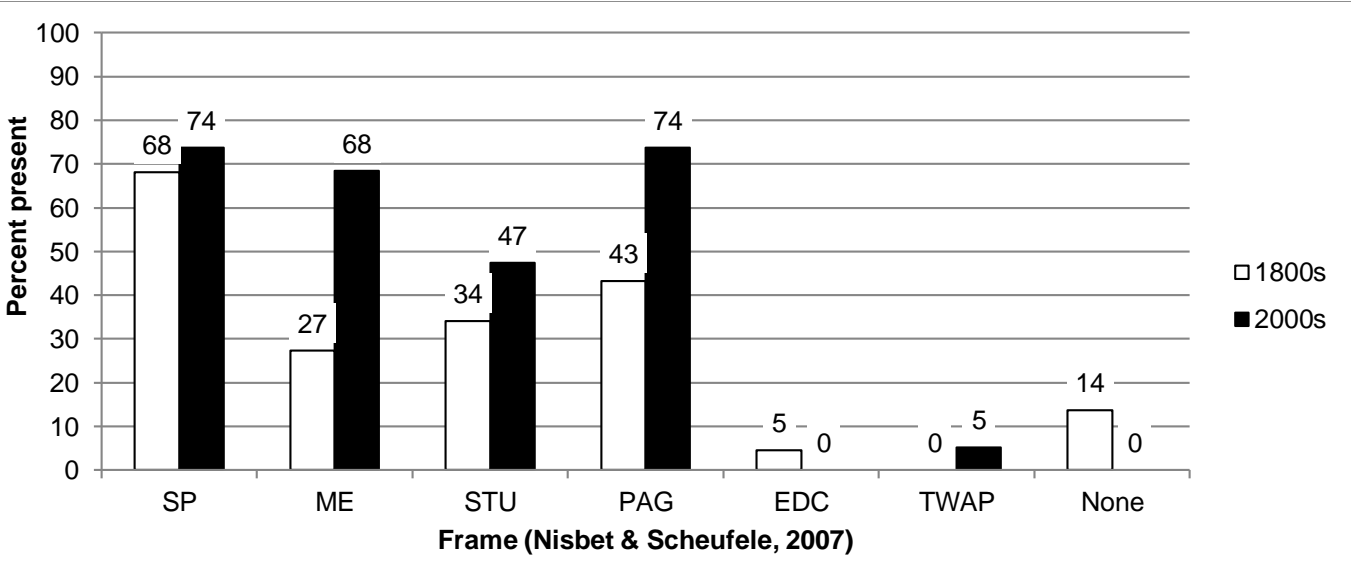

(c)

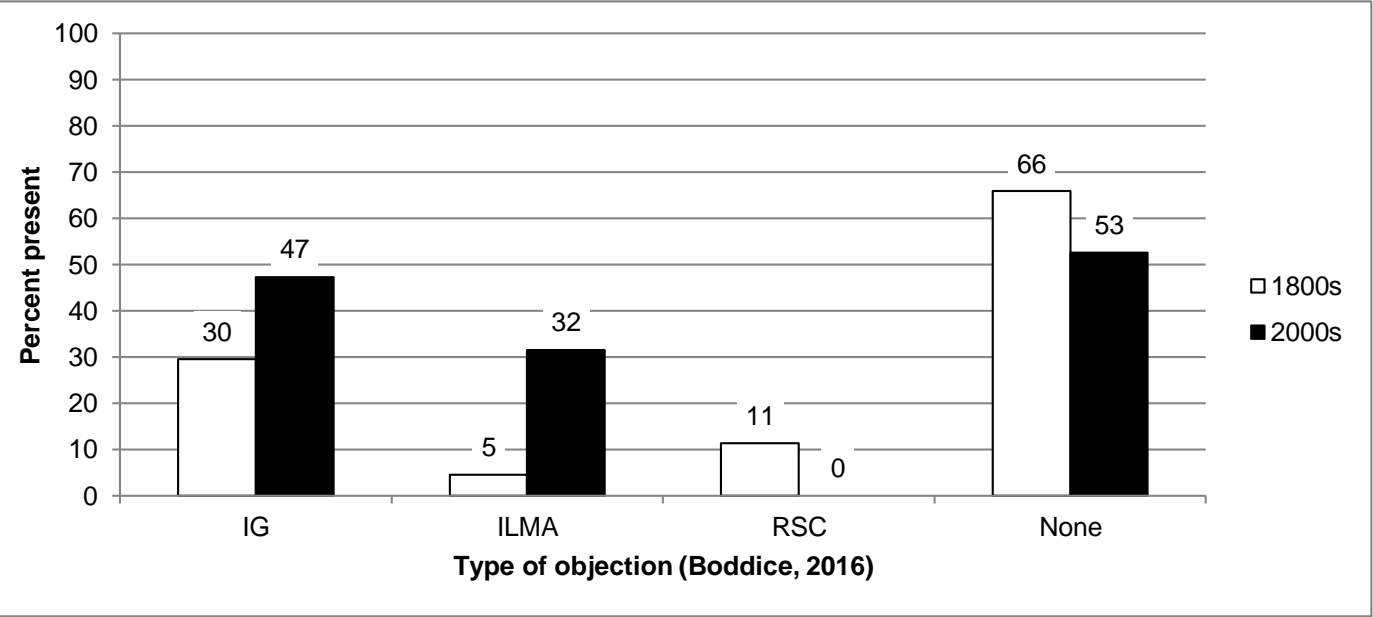

Figure 1. Each graph shows the percentage of Sydney Gazette articles ('1800s') and 2016 texts ('2000s') for which a given mode of rhetoric, frame or objection type were coded 'present'. (a) Aristotle's modes of rhetoric. (b) Nisbet and Scheufele's [2007] frames for science reporting $(\mathrm{SP}=$ social progress; $\mathrm{ME}=$ morality/ethics; $\mathrm{STU}=$ scientific/technical uncertainty; PAG=public accountability/governance; $\mathrm{EDC}=$ economic development/competition; TWAP=third way/alternative path). (c) Boddice's [2016] three types of objection to vaccination (IG=ignorance; ILMA=ideologies related to individual liberty or mistrust in authority; $\mathrm{RSC}=$ objections based on religion, sex or class). 
praising vaccination, for example discussing the "indebtedness" of vaccinated people to the "inestimable", "providentially offered" "blessing" of the vaccine, or deploring the "dreadful contagion" and "pestilential evil" of smallpox. The second was strong negative language appealing to colony residents to vaccinate their children when losing the vaccine was a risk. For example, a long letter from Principal Surgeon Thomas Jamison on 19 January 1806 was almost entirely a pathos-based appeal to parents, stating: "If they do not embrace the present opportunity they may repent hereafter, when too late, of the great injustice they have done to their children", and "I can only lament their obstinancy, and express my sorrow for the injury done their infant families." On 14 October 1804 he had expressed similar sentiments: "the most distressing reprehensibility may accrue to them from their remissness in the preservation of their Offspring."

In contrast, when pathos was employed in 2016, it was generally more restrained. Eight texts (42\%) used it, but half of those were Victorian video transcripts. The videos focused on personal stories, one of parents whose son is unable to receive vaccinations because of an immune deficiency disorder, and another about a child too young to be vaccinated who contracted chickenpox from an unvaccinated child. Pathos in these videos was used to speak to other parents on the same 'level', to create a connection through a scenario and emotions that parents may be able to identify with, for example: "A lot of guilt set in that I hadn't protected my daughter... I would not like to see any other family go through what my daughter, myself and my family have gone through", and "It [a]ffects not just your child... they rely on us". Where pathos appeared elsewhere in the 2016 dataset, in texts written in a 'government voice' rather than taking the form of personal testimony, it was used sparingly and comprised only a minor component.

Frames

Of the eight potential frames identified by Nisbet and Scheufele [2007], four were coded present in both datasets. Social progress, public accountability/governance, morality/ethics and scientific/technical uncertainty frames appeared regularly in both eras. Each era also demonstrated a fifth frame: a minor economic development/competitiveness frame appeared in two Gazette articles comparing Britain's vaccination commitment to other countries, and a third way/alternative path appeared in one 2016 text aimed primarily at health practitioners. Nisbet and Scheufele's conflict/strategy and Pandora's Box/Frankenstein's monster/runaway science frames did not appear.

Social progress was the most common frame for Gazette articles, appearing in $68 \%$ as a link between vaccination and the improvement of society and humanity's lot. It was also one of the most prevalent frames for the 2016 material, appearing in $74 \%$ of texts, where it was similarly used to convey the effectiveness of child vaccination, and its success in reducing disease prevalence in society.

A public accountability/governance frame was equally prominent in 2016 (74\% of texts), and was often employed in Gazette articles (43\%). However, it manifested differently in each. In the Gazette material we identified this frame when articles highlighted colonial authorities' actions taken in the public interest. In 2016 it manifested as a more abstract idea of 'the public good', emphasizing everyone's 
responsibility to each other rather than government specifically, for example: "Immunisation not only protects your own family, but also others by helping control serious diseases in our community" (Queensland - Benefits of Immunisation).

This appeal to caring for the wider community rather than just individuals also corresponded to a relatively weak morality/ethics frame in some 2016 texts. However, the morality/ethics frame was stronger in material targeting specific audiences. In South Australia the 'Help Me Stay Strong' campaign targeting parents and caregivers of Aboriginal children had a recurrent message, "to give your child the best start in life, get their immunisations on time to help keep them safe against disease" (emphasis added). The Victorian 'Immunity for Community' campaign similarly used the frame in many of its videos: "Why on earth would you not save your child the experience of disability, why wouldn't you vaccinate?" (Dr. Margaret's story); "What I want to say to parents is thank you for immunising your children because it keeps my children safe as well" (Ros' story). Overall the morality/ethics frame appeared in $68 \%$ of 2016 texts. In the Gazette dataset, the frame appeared in $27 \%$ of articles, and was always accompanied by pathos rhetoric. Like the 2016 material, it sometimes manifested as appeals to vaccinate for all humanity's benefit, but more often emphasized the heartbreak resulting from not vaccinating one's own children, using the strong pathos language described above.

Scientific/technical uncertainty was used to frame arguments in 34\% of Gazette articles. In almost all cases the argument assured readers of vaccine science's certainty via logos and ethos type appeals. There was one exception: the article about doctors in the past treating smallpox by bleeding was highly critical of medical professionals in general (22 February 1817). It may be significant that it was printed when no vaccination campaign was active in the colony. The scientific/technical uncertainty frame was used in nine of the 2016 texts, and similarly to the Gazette was employed to state the certainty of the science via logos appeals.

\section{Boddice's three types of objection}

In neither era did the campaigns address extensively the three types of objection listed by Boddice. Sixty-six percent of Gazette articles and 53\% of 2016 texts did not directly address any of them.

Ignorance was the objection type most commonly addressed in both eras. Thirty percent of Gazette articles overtly noted public ignorance as a source of resistance to vaccination, or explicitly set out to present 'the facts' as if to an ignorant audience. Half the 2016 texts (47\%) appeared to address ignorance, mainly from Queensland, South Australia and Victoria. The Queensland website had a section called 'Doing Further Research', aimed at people who wish to know more about vaccination safety or necessity, equipping them with an understanding of what constitutes credible information sources. For example it stated, "Be wary of people who proclaim that they, and only they, have discovered the 'hidden truth'."

This example can also be seen as implicitly addressing questions of trust in the establishment, by acknowledging that people might seek alternative sources of expertise. Discussion of trust in authority was identified in six 2016 texts, usually in relation to protocols for safety testing vaccines ("They are not included in the National 
Immunisation Program until they have been approved for use by the Therapeutic Goods Administration to ensure they meet strict safety guidelines and are evaluated to ensure they are effective", National Immunisation Program - Putting Safety First), or when referring people to sources of information ("do talk to the clinic or to your health professional, get informed, then you can focus on all the other important decisions that we as parents have to make", New South Wales - Understanding Childhood Immunisation DVD transcript). However, such acknowledgements are more re-assertions of authority than empathetic engagement with people's trust issues. The same is true for one of the two Gazette articles addressing questions of general mistrust in the establishment. The Jennerian Society material seemed determined to address questions of trust by listing a variety of bodies supporting vaccination, including royalty, nobility, mercantile and commercial gentlemen and the medical establishment, but all those listed could still be considered integral to the establishment, so this source of objection was not addressed deeply. The article about treating smallpox with bleeding was critical of the medical establishment, but mocked its older techniques, possibly implicitly endorsing more modern techniques like vaccination.

Five Gazette articles (11\%) mentioned religion, class or economic status in a way that suggested links between them and suspicion of vaccination. For example, the Jennerian Society material and its 1818 adaptation included a sample address for clergy to use at baptisms, addressing religious objections. It also addressed issues of poverty by discussing the financial burden of smallpox, and stating, "The New Inoculation recommends itself to all classes", "without expence [sic] by the Poor, for whose immediate benefit the Royal Jennerian Society is established." In two articles, authors recognized class-based objections by disparaging the obstinacy of "the lower orders", but dismissed such concerns as ignorant rather than trying to empathize with objectors. This category of objection was not identified within the 2016 texts.

These results suggest that despite 200 years of progress in both vaccination science and communication studies, Australian government strategies in vaccination campaigns have not changed much, and in some cases appear to have gone backward.

The dominant approach taken by historical and current Australian governments has relied on facts-based, or logos, arguments to convince people to vaccinate. While an important element, this ignores a growing understanding within science communication that facts alone are not enough to convince someone to adopt behaviours or accept ideas [Bray, France and Gilbert, 2012; Longnecker, 2016]. Studies have shown that addressing misinformation about vaccination with more 'education' is usually ineffective [Kata, 2010]. While a predominantly logos approach may have made sense when the science was new and knowledge minimal, we know it is not the case now that the science is well-established and knowledge widely available. The 'facts' that dominate present day approaches are more likely to get lost in the plethora of pro- and anti-vaccine information sources people are faced with. Given this, it is particularly interesting that using a combination of approaches, like incorporating pathos with logos and ethos, was more common in the early era. 
Anti-vaccination websites are typically among the first hits in an internet search [Bean, 2011], and they reject the scientific consensus in favour of their own interpretation primarily because of larger issues of trust [Kata, 2010]. As Boddice [2016] notes, addressing such questions of trust is essential for campaigns to succeed. Yet in both eras, the scientific perspective was emphasized via logos arguments, ethos endorsement from establishment bodies, and social progress frames linking vaccination successes to public well-being. In neither era were issues of trust or identity-based objections dealt with often (though more often in the 1800s). It is notable that this general approach has not changed in 200 years except in non-government materials [e.g. Attwell and Freeman, 2015], despite widespread understanding of this point among communications researchers. Changes to the type of authorities referred to in ethos appeals has changed - from royalty to scientific protocols - but the authorities mentioned remain identified with establishment power, so issues of trust in the establishment remain unaddressed.

Arguably the very idea of establishment power is more suppressed in the 2016 texts than the Gazette articles. This is apparent in both the different ethos authorities referred to and the different applications of the public accountability/governance frame. The Gazette did not seem to hide its 'us and them' view of the relationship between the ruling class and the ruled, reaching out its governing hand to encourage the underprivileged to join royalty, bishops, doctors and merchants in reaping the benefits of vaccination. There is a sense of material privilege being shared by the powerful for one time only. In contrast, governments largely made themselves invisible in the 2016 material, instead investing responsibility in abstract concepts of community and the scientific method. This was perhaps an attempt to make readers feel empowered by creating the impression that they were operating within a rational, level playing field in a society of equals. But this sentiment is likely to seem disingenuous to people who feel disenfranchised, especially in an age of state coercion. There is value in governments (and scientists) overtly acknowledging their position of establishment authority, and understanding how it can obstruct attempts at a logos-based conversation, rather than pretending it doesn't exist.

The notion of individual responsibility was prevalent in both sets of texts, but with different focal points. In the Gazette it was directed at parents and their responsibility to protect their child, while the 'public good' argument of keeping the vaccine alive in the colony was secondary. In the 2016 texts the dominant thread urged people to vaccinate for the benefit of the greater community, while the individual consequences of not vaccinating remained rhetorically marginal. This may be because smallpox presented a more real threat in 1806 than deadly infectious diseases in 2016, so parental guilt was a more effective rhetorical strategy, while now governments emphasize herd immunity altruism. Connected to this is the striking difference in the use of pathos between the two eras. Principal Surgeon Jamison had no qualms about reaching out to parents with deeply emotional appeals in the 1800s. In 2016 pathos was largely reserved for people's personal stories in a single jurisdiction (the Victorian Immunity for Community videos) - the 'government voice' in all jurisdictions generally lacked pathos. The absence of pathos in most governments' current approaches may be a shortcoming of the campaign. Presumably herd immunity altruism can be cultivated by pathos as much as can parental guilt. While it seems likely that individual Australians sharing their experiences, as in the Victorian example, would have more persuasive 
value today than an emotional appeal from a government representative, social experiments putting pathos back into the government voice, for example via the current Health Minister or the Chief Medical Officer, may prove interesting.

More specifically, since viewing anti-vaccination websites increases vaccine hesitancy [Betsch et al., 2010], we echo Stahl et al. [2016] in saying that government health agencies must 'take the fight to the Internet battlefield', but not just with more information. In addition to anti-vaccination groups, news media and interpersonal sources such as friends and family can also contribute to vaccine attitudes [Dixon and Clarke, 2013], and all these sources have online presences and communication channels, especially via social media. Social media platforms are notably not restricted to logos-type information provision, but are venues for emotional expression and personal conversations. Intelligent social media interventions by governments may parallel Principal Surgeon Jamison's personal appeals to the public, and his use of pathos, logos and ethos together for maximum impact. Tirdatov [2014] found that crowd-funding ventures using all three rhetorical modes were the most successful, so governments should learn from that. They must acknowledge not only the scientific arguments, but the other factors which influence personal perceptions of risk and decision making. These include ideological disagreements about state power versus individual rights, and feelings of disenfranchisement in the face of establishment authority. Governments and their scientific representatives need to think seriously about how to present themselves in light of this.

The findings presented here are derived from the Australian context, but are echoed in the international literature. Members of the public who are unsure or simply against vaccination are highly visible on social media [Pereira et al., 2013] and are more likely to share or discuss information which could affect public perception and acceptance of childhood vaccination [McKeever et al., 2016]. This cannot be countered merely by recitation of fact. Public health campaigns, especially on social media, need to invite emotional dialogue to be more successful, acknowledging and respecting the real fears of an audience who have doubts about the ability of the medical profession to help them [Bail, 2016]. Advocates for childhood vaccination need to employ greater pathos in their communication — simply stating 'these are the scientific facts...' is not, and never will be, enough. Somewhere in the last 200 years it appears that feelings and emotions have been downplayed, or at worst ignored, victims of the general rationalisation and bureaucratisation of western society during that period [Weber, 1978]. To gain any traction in addressing vaccine hesitancy, government health agencies need to acknowledge the role of emotion in creating effective communication strategies [Bail, 2016].

We began this paper by outlining the three historically recurring objections about vaccination identified by Boddice [2016]. In our examinations of the texts, it was clear that a majority of government communications are not addressing these fears at all. Governments must adopt communication processes that build rapport and trust, particularly with parents, and "recognize that parents' trust in the source of information may be more important than the information itself" [Danchin and Nolan, 2014, p. 71]. Government vaccination programs have diversified in the past two centuries, changing with developments in research, and it is time their communication strategies did too. 
Attwell, K. and Freeman, M. (2015). 'I Immunise: An evaluation of a values-based campaign to change attitudes and beliefs'. Vaccine 33 (46), pp. 6235-6240. DOI: $10.1016 / \mathrm{j}$. vaccine.2015.09.092.

Australian Government (2015). About the Program.

URL: http://www.immunise.health.gov.au/internet/immunise/publishing .nsf/Content/about-the-program (visited on 12th October 2016).

- (2016a). National Immunisation Program Schedule.

URL: http://www.immunise.health.gov.au/internet/immunise/publishing .nsf/Content/national-immunisation-program-schedule (visited on 12th October 2016).

- (2016b). Vaccination Data Hub. URL: http://www. immunise .health.gov . au/inte rnet/immunise/publishing.nsf/Content/vaccination-data (visited on 13th October 2016).

Bail, C. A. (2016). 'Emotional Feedback and the Viral Spread of Social Media Messages About Autism Spectrum Disorders'. American Journal of Public Health 106 (7), pp. 1173-1180. DOI: 10.2105/ajph . 2016.303181.

Bauer, M. W., Allum, N. and Miller, S. (2007). 'What can we learn from 25 years of PUS survey research? Liberating and expanding the agenda'. Public Understanding of Science 16 (1), pp. 79-95. DOI: 10.1177/0963662506071287.

Bean, S. J. (2011). 'Emerging and continuing trends in vaccine opposition website content'. Vaccine 29 (10), pp. 1874-1880. DOI: 10.1016/j . vaccine.2011.01.003.

Bennett, M. J. (2009). 'Smallpox and Cowpox under the Southern Cross: The Smallpox Epidemic of 1789 and the Advent of Vaccination in Colonial Australia'. Bulletin of the History of Medicine 83 (1), pp. 37-62. DOI: $10.1353 / \mathrm{bhm} .0 .0167$.

Betsch, C., Renkewitz, F., Betsch, T. and Ulshöfer, C. (2010). 'The Influence of Vaccine-critical Websites on Perceiving Vaccination Risks'. Journal of Health Psychology 15 (3), pp. 446-455. DOI: 10.1177/1359105309353647.

Bhattacharya, S. and Brimnes, N. (2009). 'Introduction: Simultaneously Global and Local: Reassessing Smallpox Vaccination and Its Spread, 1789-1900'. Bulletin of the History of Medicine 83 (1), pp. 1-16. DOI: 10.1353/bhm. 0.0194.

Boddice, R. (2016). 'Vaccination, Fear and Historical Relevance'. History Compass 14 (2), pp. 71-78. DOI: 10.1111/hic3.12297.

Bray, B., France, B. and Gilbert, J. K. (2012). 'Identifying the Essential Elements of Effective Science Communication: What do the experts say?' International Journal of Science Education, Part B 2 (1), pp. 23-41. DOI: $10.1080 / 21548455.2011 .611627$.

Collins, J., Alona, I., Tooher, R. and Marshall, H. (2014). 'Increased awareness and health care provider endorsement is required to encourage pregnant women to be vaccinated'. Human Vaccines \& Immunotherapeutics 10 (10), pp. 2922-2929. DOI: $10.4161 / 21645515.2014 .971606$.

Danchin, M. and Nolan, T. (2014). 'A positive approach to parents with concerns about vaccination for the family physician'. Australian Family Physician 43 (10), pp. 690-694.

Dixon, G. N. and Clarke, C. E. (2013). 'Heightening Uncertainty Around Certain Science: Media coverage, false balance, and the autism vaccine controversy'. Science Communication 35 (3), pp. 358-382. DOI: 10.1177/1075547012458290.

Durbach, N. (2000). "“They Might As Well Brand Us": Working-Class Resistance to Compulsory Vaccination in Victorian England'. Social History of Medicine 13 (1), pp. 45-63. DOI: $10.1093 / \mathrm{shm} / 13.1 .45$. 
Hendel, S. (2016). 'No jab, no pay' disadvantages migrant children. URL: http://thecon versation.com/no-jab-no-pay-disadvantages-migrant-children-66387 (visited on 3rd October 2016).

Kata, A. (2010). 'A postmodern Pandora's box: Anti-vaccination misinformation on the Internet'. Vaccine 28 (7), pp. 1709-1716. DOI: $10.1016 / \mathrm{j}$. vaccine. 2009.12.022.

Leask, J., Willaby, H. W. and Kaufman, J. (2014). 'The big picture in addressing vaccine hesitancy'. Human Vaccines E Immunotherapeutics 10 (9), pp. 2600-2602. DOI: $10.4161 / \mathrm{hv} .29725$.

Leshner, G., Bolls, P. and Thomas, E. (2009). 'Scare 'Em or Disgust 'Em: The Effects of Graphic Health Promotion Messages'. Health Communication 24 (5), pp. 447-458. DOI: 10.1080/10410230903023493.

Longnecker, N. (2016). 'An integrated model of science communication - More than providing evidence'. JCOM 15 (05), Y01. URL: https://jcom.sissa.it/archive/15/05/JCOM_1505_2016_Y01.

Mark, C. and Rigau-Pérez, J. G. (2009). ‘The World's First Immunization Campaign: The Spanish Smallpox Vaccine Expedition, 1803-1813'. Bulletin of the History of Medicine 83 (1), pp. 63-94. DOI: 10.1353/bhm.0.0173.

Markic, S. and Eilks, I. (2013). 'Potential changes in prospective chemistry teachers' beliefs about teaching and learning-a cross-level study'. International Journal of Science and Mathematics Education 11 (4), pp. 979-998. DOI: $10.1007 / \mathrm{s} 10763-013-9417-9$.

Marriner, C. (2016). Federal government's 'no jab, no pay' law sparks run on vaccines. Sydney Morning Herald. URL: http://www. smh.com.au/nsw/federal-governm ents-no-jab-no-pay-law-sparks-run-on-vaccines-20160219-gmyusd.html (visited on 20th February 2016).

McCall, R. and Groark, C. (2007). A Perspective on the History and Future of Disseminating Behavioral and Social Science. Ed. by R. McCall and C. Groark. Thousand Oaks, CA, U.S.A.: Sage, pp. 15-32. DOI: 10.4135/9781412976930.n2.

McKeever, B. W., McKeever, R., Holton, A. E. and Li, J.-Y. (2016). 'Silent Majority: Childhood Vaccinations and Antecedents to Communicative Action'. Mass Communication and Society 19 (4), pp. 476-498. DOI: $10.1080 / 15205436.2016 .1148172$.

McWhirter, R. (2008). “Lymph or Liberty': Responses to Smallpox Vaccination in the Eastern Australian Colonies'. Ph.D. University of Tasmania. URL: http://eprints . utas . edu . au/8077/.

Mikulak, A. (2011). 'Mismatches between "Scientific" and "Non-Scientific" Ways of Knowing and Their Contributions to Public Understanding of Science'. Integrative Psychological and Behavioral Science 45 (2), pp. 201-215. DOI: $10.1007 / \mathrm{s} 12124-011-9157-8$.

Murdoch, L. (2015). 'Carrying the Pox: The Use of Children and Ideals of Childhood in Early British and Imperial Campaigns Against Smallpox'. Journal of Social History 48 (3), pp. 511-535. DOI: 10.1093/jsh/shu112.

National Centre for Immunisation Research \& Surveillance (2016). No Jab No Play, No Jab No Pay Policies. URL: http: //www .ncirs . edu .au/consumer-resources/n o-jab-no-play-no-jab-no-pay-policies/ (visited on 18th September 2016).

Nisbet, M. C. and Scheufele, D. A. (2007). 'The Future of Public Engagement I The Scientist Magazine'. The Scientist 21 (10), pp. 39-45.

URL: http://www. the-scientist.com/?articles.view/articleNo/25447/tit le/The-Future-of-Public-Engagement/. 
Nisbet, M. C. and Lewenstein, B. V. (2002). 'Biotechnology and the American Media The Policy Process and the Elite Press, 1970 to 1999'. Science Communication 23 (4), pp. 359-391. DOI: 10.1177/107554700202300401.

Orthia, L. A. (2016). "“Laudably Communicating to the World”: Science in Sydney's Public Culture, 1788-1821'. Historical Records of Australian Science 27 (1), pp. 1-12. DOI: $10.1071 / \mathrm{hr} 15018$.

Peatling, S. (2015). Health experts question Turnbull government's 'no jab no play' policy. Sydney Morning Herald. URL: http://www.smh.com.au/federal-politics/po litical-news/health-experts-question-turnbull-governments-no-jab-no - play-policy-20151102-gkognk. html (visited on 2nd September 2015).

Pereira, J. A., Quach, S., Dao, H. H., Kwong, J. C., Deeks, S. L., Crowcroft, N. S., Quan, S. D. and Guay, M. (2013). 'Contagious Comments: What Was the Online Buzz About the 2011 Quebec Measles Outbreak?' PLoS ONE 8 (5). Ed. by L. G. Filion, e64072. DOI: 10.1371/journal . pone.0064072.

Perez, S., Fedoruk, C., Shapiro, G. K. and Rosberger, Z. (2016). 'Giving Boys a Shot: The HPV Vaccine's Portrayal in Canadian Newspapers'. Health Communication 31 (12), pp. 1527-1538. DOI: 10.1080/10410236.2015.1089466.

Smith, M. J. (2015). 'Promoting Vaccine Confidence'. Infectious Disease Clinics of North America 29 (4), pp. 759-769. DOI: 10.1016/j . idc. 2015.07.004.

Stahl, J.-P., Cohen, R., Denis, F., Gaudelus, J., Martinot, A., Lery, T. and Lepetit, H. (2016). 'The impact of the web and social networks on vaccination. New challenges and opportunities offered to fight against vaccine hesitancy'. Médecine et Maladies Infectieuses 46 (3), pp. 117-122. DOI: $10.1016 / \mathrm{j}$.medmal .2016.02.002.

Tirdatov, I. (2014). 'Web-Based Crowd Funding: Rhetoric of Success'. Technical Communication 61 (1), pp. 3-24.

Tung, I. L. Y., Machalek, D. A. and Garland, S. M. (2016). 'Attitudes, Knowledge and Factors Associated with Human Papillomavirus (HPV) Vaccine Uptake in Adolescent Girls and Young Women in Victoria, Australia'. PLoS One 11 (8), e0161846, pp. 1-15. DOI: 10.1371/journal . pone. 0161846.

Weber, M. (1978). 'Bureacracy'. In: Economy and Society. Berkeley, U.S.A.: University of California Press, pp. 956-1005.

Merryn McKinnon and Lindy Orthia are equal contributors and co-first authors of this paper.

Merryn McKinnon is a lecturer in science communication at the Australian National Centre for the Public Awareness of Science (CPAS), the Australian National University. E-mail: merryn.mckinnon@anu.edu.au.

Lindy Orthia is a senior lecturer in science communication at CPAS. She is also an MPhil candidate at the Australian National University School of History, through which this research was supported by an Australian Government Research Training Program (RTP) Scholarship. E-mail: lindy.orthia@anu.edu.au.

\section{How to cite}

McKinnon M. and Orthia L. A. (2017). 'Vaccination communication strategies: What have we learned, and lost, in 200 years?'. JCOM 16 (03), A08.

This article is licensed under the terms of the Creative Commons Attribution - NonCommercial - NoDerivativeWorks 4.0 License. ISSN 1824-2049. Published by SISSA Medialab. jcom.sissa.it 